\title{
Prostate Cancer cM0 TNM Finding v8
}

National Cancer Institute

\section{Source}

National Cancer Institute. Prostate Cancer cMo TNM Finding v8. NCI Thesaurus. Code C140122.

Prostate cancer without evidence of distant metastasis. (from AJCC 8th Ed.) 